OPEN ACCESS

Edited by:

Jun Zhou,

University of Massachusetts Lowell, United States

Reviewed by: Jiakai Gao,

Henan University of Science and

Technology, China Hongbiao Cui,

Anhui University of Science and

Technology, China

${ }^{*}$ Correspondence:

Hongyan Liu

hyliu@gzu.edu.cn

Specialty section:

This article was submitted to

Toxicology, Pollution and

the Environment,

a section of the journal

Frontiers in Environmental Science

Received: 24 March 2021

Accepted: 18 May 2021

Published: 15 June 2021

Citation:

Liu K, Liu H, Zhou X, Chen Z and Wang $X$ (2021) Prediction of Cadmium Transfer From Soil to Potato in Karst

Soils, China.

Front. Environ. Sci. 9:684887. doi: 10.3389/fenvs.2021.684887

\section{Prediction of Cadmium Transfer From Soil to Potato in Karst Soils, China}

\author{
Ke Liu, Hongyan Liu*, Xianyong Zhou, Zhu Chen and Xulian Wang \\ College of Agriculture, Guizhou University, Guiyang, China
}

Contamination of food with the heavy metal $\mathrm{Cd}$ is a significant global concern. In this study, a field survey was performed to investigate the characteristics of $\mathrm{Cd}$ transfer from soil to potato tubers $(n=105)$. The results showed that the bioaccumulation factor of the potato tuber ranged from about 0.1 to 1 . The soil threshold of $\mathrm{Cd}$ derived from the cumulative probability distribution was $0.15 \mathrm{mg} \mathrm{kg}^{-1}$ in order to protect $95 \%$ of potatoes. Additionally, prediction models for $\mathrm{Cd}$ transfer were constructed based on soil properties and the concentration of $\mathrm{CaCl}_{2}$-extractable soil $\mathrm{Cd}$. The results of the analysis showed that $\mathrm{pH}$ was the critical factor affecting Cd uptake by potatoes. Additionally, the $R^{2}$ of different empirical models increased from 0.354 to 0.715 as the number of soil parameters was increased, and the predicted soil $\mathrm{Cd}$ concentration approached the measured values at values of about $0-15 \mathrm{mg} \mathrm{kg}^{-1}$. The results of this study suggest that the probability distribution method was stricter than the empirical prediction models for estimating the ecological risk of Cd contamination of potatoes in karst soils.

Keywords: cadmium, potato, soil threshold, prediction model, probability statistics

\section{INTRODUCTION}

With the development of industry and agriculture in China, contamination of food by the trace metal cadmium (Cd) has become a public concern due to its toxicity and persistence in soil. Soil Cd has negative effects on crop growth and production (e.g., wheat and rice) and can affect human health through the food chain (Diao, et al., 2005). Potatoes are an important food resource in China, which has the largest potato production in the world. In 2019, the Chinese potato planting area reached 4.7895 million hectares, and China's potato production of 91.938 million tons accounted for $24.91 \%$ of the global total. The consumption of potatoes that have accumulated $\mathrm{Cd}$ from contaminated soil is a major issue because potatoes are widely planted around the world. For example, excessive $\mathrm{Cd}$ accumulated in potatoes (about $0.18 \mathrm{mg} \mathrm{kg}^{-1}$ ) was shown to be caused by Cd pollution $(1.25 \mathrm{mg}$ $\mathrm{kg}^{-1}$ ) in sierozem soil in Gansu Province, China (Liu, et al., 2019). Soil minerals in karst areas have high heavy metal content, and the metals in these minerals have been brought to the soil surface by geological and biological processes. Metal elements that have migrated to the surface have weak migration ability in the soil. Moreover, human activities in karst areas lead to a certain amount of heavy metal contamination in the local soil, further increasing the content of heavy metals and eventually leading to abnormal metal content (Tang, et al., 2021; Zhang, et al., 2021). Therefore, it is necessary to study the transfer of $\mathrm{Cd}$ from soil to crops in order to better control soil risks and ensure food safety.

In general, plant $\mathrm{Cd}$ concentrations are correlated with the soil total $\mathrm{Cd}$. For example, soil total $\mathrm{Cd}$ accounted for $64 \%$ of the variation in the Cd concentration in potato tubers based on the results of stepwise multiple regression $(n=49)$ when irrigation was performed with river water contaminated by mining (Carla, et al., 2007). However, McLaughlin et al., (1997) found no significant correlation 
between the Cd content in soil and that in potato tubers in a study of 352 potato production sites in Australia. These contradictory results may be due to differences in study regions, experimental conditions, and plant varieties. Soil total Cd concentrations can indicate the pollution status of soil, but cannot accurately reflect the pollution risk of soil to plants. The content of bioavailable Cd in soil mainly refers to the $\mathrm{Cd}$ that can be absorbed by crops during the crop growth period. In fact, many researchers have found that plant $\mathrm{Cd}$ content is closely related to the available $\mathrm{Cd}$ content in soil that is extractable by chemical extractants like $\mathrm{CaCl}_{2}$ or $\mathrm{CH}_{3} \mathrm{COONH}_{4}$. The Tessier sequential extraction procedure can be used to extract five fractions of $\mathrm{Cd}$ with different reagents. For instance, Wei et al., 2020 used the fivestep batch metal fractionation method to study the influence of spent mushroom substrate on $\mathrm{Cd}$ immobilization and soil amendment, and Mitchell et al., 2020 employed a similar method to explore the impact of low-temperature biochar on the Cd concentration of calcareous river sediments. While single extraction methods seem to be more convenient and practical, Cd and $\mathrm{Zn}$ extracted by $0.01 \mathrm{M} \mathrm{CaCl}_{2}$ were successfully used to predict Cd levels in brown rice planted in paddy fields across the western plains in Taiwan (Römkens, et al., 2009; Kara et al., 2004) assessed the soil Cd content in sowing regions of potato fields from a total of 45 different sampling stations in Turkey by using $\mathrm{HCl}+\mathrm{H}_{2} \mathrm{SO}_{4} \cdot 0.01 \mathrm{M} \mathrm{CaCl}_{2}$ is a commonly used chemical extractant in various extraction methods used to research the bioavailability of $\mathrm{Cd}$ because $0.01 \mathrm{M} \mathrm{CaCl}_{2}$ solution matches the soil with respect to $\mathrm{pH}$, concentration, and composition (Zhou, et al., 2019). Additionally, the physical and chemical properties of soil also have a great influence on the accumulation and absorption of $\mathrm{Cd}$ by crops. For example, soil $\mathrm{pH}$ and concentrations of $\mathrm{Cl}$ and $\mathrm{Zn}$ were found to be the main factors affecting the $\mathrm{Cd}$ concentration of potato tubers in Australia (McLaughlin et al., 1997). Furthermore, using a stepwise regression model, Rafiq et al., 2014 showed that the Cd phytoavailability of pak choi grown in Chinese soils was dependent on soil properties such as $\mathrm{pH}$ and organic matter content.

Empirical models such as Freundlich-type models have been widely used to study the accumulation and transfer of heavy metals between soil and plants. The Cd concentrations of plants and soil, as well as bioaccumulation factors (BAFs), could be added to Freundlich-type models in order to predict the phytoavailability of metals for the evaluation of environmental quality. For example, the Freundlich relationship was applied to the empirical modeling of soil parameters including clay content, soil organic matter, cation exchange capacity, and soil $\mathrm{Cd}$ to predict the Cd content in wheat grain (François, et al., 2009). Additionally, multiple linear regression models have been used to predict the metal content of plants. For instance, the uptake and transfer of $\mathrm{Cd}$ in potatoes $(n=10)$ was predicted based on metal bioavailability (ethylenediamine tetraacetic acid extract) and soil properties in two contaminated regions of Kosovo (Zogaj and Düring, 2016). Moreover, Xu et al., 2019 used a polynomial model to derive Cd soil-plant relationships and soil criteria in order to provide suggestions for food safety and soil management. In recent years, the cumulative probability distribution method has been applied to study the soil threshold Cd concentrations in order to improve crop protection. For example, species sensitivity distribution (SSD) methodology is mainly used to determine the concentration of a toxicant that is protective of different ratios of species $(50,90$, or $95 \%)$ in the environment. At present, the probability distribution functions used to fit the toxicological data of pollutants include log-normal, log-logistic, and Burr III type models. Liu et al., 2015 derived the soil threshold of $\mathrm{Cd}$ in a wheat-producing area of China $(n=18)$ based on probability estimation using the log-normal function. Moreover, Ding et al., 2016 used the SSD to obtain the soil thresholds of $\mathrm{Pb}$ for root vegetables with a BAF-based prediction model depending on the combination of soil $\mathrm{pH}$ and cation exchange capacity (CEC). Additionally, Ding et al., 2018 applied a similar cumulative probability distribution (SSD) to determine the soil threshold of Cd based on 12 root vegetable cultivars fitted by a Burr type III distribution with three different Cd treatments in various types of soil. These studies show that linear regression models can be used to describe the transport and enrichment of heavy metals, and the relationships between heavy metals in soil and plants. Therefore, probability statistics such as the SSD method can be used to perform risk assessment of pollutants at the level of the whole ecosystem and set soil thresholds.

Paired soil and plant samples $(n=105)$ were collected, and concentrations of $\mathrm{Cd}$ were measured. The present study aimed to 1) investigate the characteristics of $\mathrm{Cd}$ transfer from soil to potato tubers in a karst area of Guizhou Province, China, 2) obtain the soil Cd threshold based on the cumulative probability distribution using the log-normal function, and 3) explore an empirical prediction model based on plant and soil $\mathrm{Cd}$ concentrations and soil factors like $\mathrm{pH}$ and organic matter in order to improve soil environmental quality and protect food safety and human health.

\section{MATERIALS AND METHODS}

\section{Sample Collection}

Field research was carried out in farmland in Guizhou Province, China. This province has a high background content of Cd due to the prevalent karst geochemical conditions, and the problem of soil $\mathrm{Cd}$ pollution is particularly prominent. For example, the relationships between soil properties and the accumulation of heavy metals in Brassica campestris L. in a karst area of Guizhou Province showed that the background levels of heavy metals in the soil of Guizhou Province are generally high due to the influence of topography and the presence of soil parent material (Zhang, et al., 2020). An analysis of the risk posed by eight typical heavy metals in soils in Guizhou Province using province-wide data available in the literature revealed that $\mathrm{Cd}$ showed a very high potential ecological risk (Yu, et al., 2021). We selected the counties of Weining, Hezhang, Ceheng, Changshun, and Leigong, each of which contains a large proportion of carbonate rocks, for sampling. Soil was collected from the upper layer of the soil $(0-20 \mathrm{~cm})$. The distance between the sampling point and the local trunk road was more than $100 \mathrm{~m}$. 
TABLE 1 | Basic soil properties.

\begin{tabular}{|c|c|c|c|c|c|c|}
\hline Soil property & Number & Average & Standard deviation & Median & Minimum & Maximum \\
\hline $\mathrm{pH}$ & 105 & 6.53 & 1.12 & 6.79 & 4.27 & 8.61 \\
\hline Organic matter $\left(\mathrm{g} \cdot \mathrm{kg}^{-1}\right)$ & 105 & 40.22 & 14.07 & 37.55 & 7.26 & 79.68 \\
\hline
\end{tabular}

\section{Sample Analysis}

The collected soil samples were air-dried and then crushed with wooden sticks before being passed through a nylon sieve with a diameter of $0.149 \mathrm{~mm}$. The collected potato samples were washed with tap water to remove surface soil particles and were then washed with distilled water, put into an oven at $105-110^{\circ} \mathrm{C}$ for $15 \mathrm{~min}$, and dried to a constant weight at $70-90^{\circ} \mathrm{C}$ in the oven. Finally, the samples were smashed for the subsequent analysis. The soil physical and chemical properties were determined by routine methods (Liu, et al., 2015), soil $\mathrm{pH}$ was determined by a glass electrode at a soil:water ratio of 1:2.5 $\left(\mathrm{g} \mathrm{ml}^{-1}\right)$, organic matter content was measured based on an oil bath heating method (potassium dichromate oxidation), and the results are shown in Table 1.

The total Cd in soil was determined as follows: we accurately weighed $0.1 \mathrm{~g}$ (accurate to $0.0001 \mathrm{~g}$ ) of the sieved soil sample and placed it in a polytetrafluoroethylene (PTFE) tank, added $3 \mathrm{ml} \mathrm{HNO}_{3}$ and $3 \mathrm{ml} \mathrm{HCl}$, and placed the capped tank in a matched steel pipe, which was sealed. The steel pipe was placed in an incubator and heated at $185^{\circ} \mathrm{C}$ at a pressure of $790 \mathrm{kPa}$ for $8 \mathrm{~h}$. After cooling to room temperature, the digestion solution was removed from the pipe, placed on an electric heating plate, heated to $160^{\circ} \mathrm{C}$, and steamed until it was viscous. The residual digestion solution was transferred to a $50 \mathrm{ml}$ volumetric flask and diluted to $50 \mathrm{ml}$ with ultrapure water.

Soil bioavailable $\mathrm{Cd}$ was determined by $\mathrm{CaCl}_{2}$ extraction. A soil sample $(2.00 \mathrm{~g})$ was passed through a $0.2 \mathrm{~mm}$ sieve and placed in a $50 \mathrm{ml}$ centrifuge tube. Then, $0.01 \mathrm{~mol} \mathrm{~L}^{-1} \mathrm{CaCl}_{2}$ solution was added and the tube was shaken for $2 \mathrm{~h}$ and centrifuged at $3,500 \mathrm{r} \cdot \mathrm{min}^{-1}$ for $5 \mathrm{~min}$. The level of $\mathrm{Cd}$ in the supernatant was detected. We accurately weighed $0.3 \mathrm{~g}$ (accurate to $0.0001 \mathrm{~g}$ ) of each plant sample, placed it in a PTFE tank, and soaked it in $6 \mathrm{ml}$ of $\mathrm{HNO}_{3}$ overnight. Then, $2 \mathrm{ml}$ of $\mathrm{H}_{2} \mathrm{O}_{2}$ solution was mixed into the above solution and the tank was covered and placed in a supporting steel pipe and sealed. Plant Cd was determined as follows: the steel pipe was placed in an oven and heated at $100^{\circ} \mathrm{C}$ for $2 \mathrm{~h}$. Next, the temperature was raised to $140^{\circ} \mathrm{C}$ for $2 \mathrm{~h}$, after which it was raised to $160^{\circ} \mathrm{C}$ for $4 \mathrm{~h}$. The method for solution transferal and detection of the plant $\mathrm{Cd}$ concentration was the same as that used for the soil samples. A total of $10 \mathrm{ml}$ of each digested sample solution was analyzed by inductively coupled plasma mass spectrometry to determine its Cd concentration (ICP-MS; Thermo Fisher Scientific, Waltham, MA, United States, and x2). Reference material GSS-5 and GSB-1 was adopted to ensure the quality control and the detected Cd concentration in soil and plant deviated about $15 \%$ from the true value.

\section{Modeling}

Statistical analysis was performed using Microsoft Excel 2010 and SPSS 22.0 software. The log-normal function was applied to fit the cumulative probability distribution curve (SSD curve) using SSD

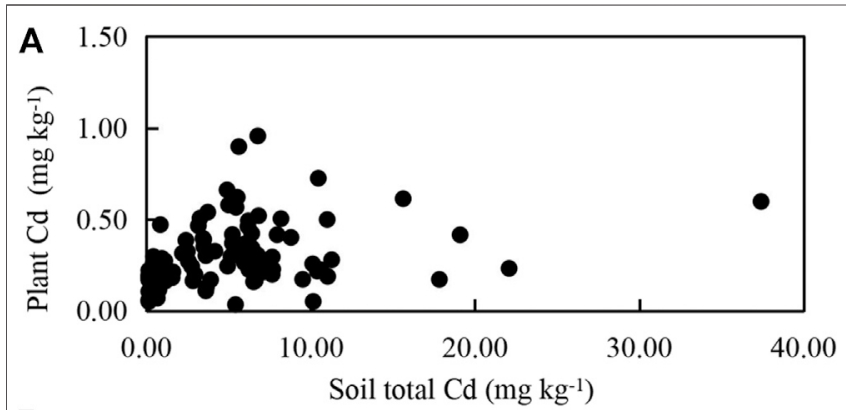

B

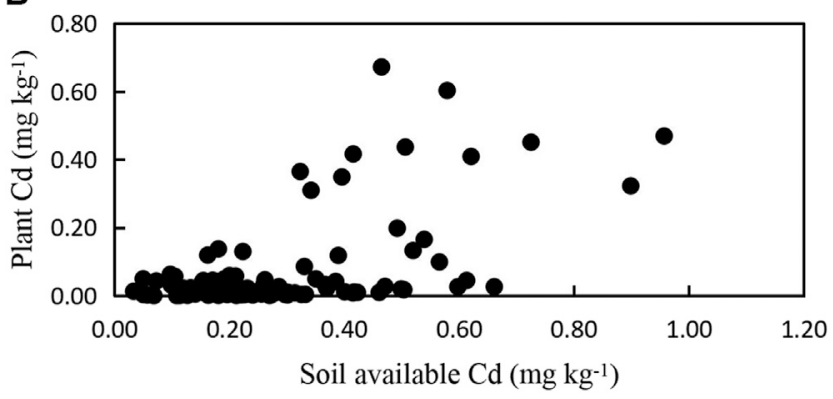

FIGURE 1 | Relationship between the plant Cd concentration and soil total $\mathrm{Cd}(\mathbf{A})$, and the relationship between the plant $\mathrm{Cd}$ concentration and soil available $\mathrm{Cd}(\mathbf{B})$

Generator V1 software. The cumulative probability distribution was obtained from the toxicological data for pollutants based on the concept of BAFs $\left(C_{\text {soil }}=0.1 / \mathrm{BAF}\right.$, $0.1 \mathrm{mg} \mathrm{kg}^{-1}$ was the limit of the Chinese food safety standard (GB 2762-2017) for Cd). The soil threshold values corresponding to different levels of protection or risk were obtained from the curve.

The BAF is the ratio of the metal concentration in plant tissues to that in the soil, and is calculated as follows:

$$
\mathrm{BAF}=\frac{\mathrm{C}_{\text {plant }}}{\mathrm{C}_{\text {soil }}},
$$

where $\mathrm{C}_{\text {plant }}$ is the $\mathrm{Cd}$ concentration in the tuber of the test plant and $\mathrm{C}_{\text {soil }}$ is the $\mathrm{Cd}$ concentration in the test soil.

The relationships among soil $\mathrm{Cd}$, plant $\mathrm{Cd}$ concentration, and soil properties were expressed by an empirical model as follows:

$$
\begin{aligned}
\log \mathrm{C}_{\text {soil }}= & \mathrm{a} \times \log \mathrm{C}_{\text {plant }}+\mathrm{b} \times \mathrm{pH}+\mathrm{c} \\
& \times \log (\text { other soil properties })+\mathrm{k},
\end{aligned}
$$

where $\mathrm{a}, \mathrm{b}$, and $\mathrm{c}$ reflected the relationships among soil $\mathrm{Cd}$, soil plant $\mathrm{Cd}$, and soil properties, while $\mathrm{k}$ was the intercept. 

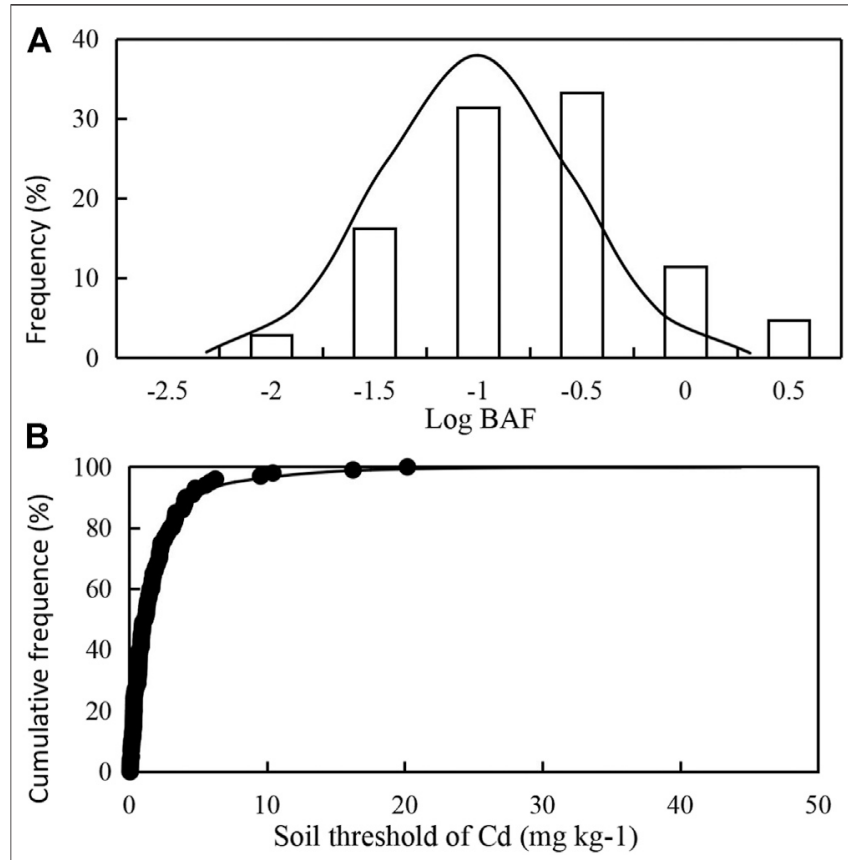

FIGURE 2 | Frequency distribution of the bioaccumulation factor (BAF) (A) and the cumulative probability distribution of the soil Cd threshold (B).

\section{RESULTS AND DISCUSSION}

\section{Probability Statistics for Soil Cd Threshold}

The total $\mathrm{Cd}$ concentration of the soil samples varied between 0.15 and $37.4 \mathrm{mg} \mathrm{kg}^{-1}$, with an average value of $4.98 \mathrm{mg} \mathrm{kg}^{-1}$, and the $\mathrm{Cd}$ concentration of the potato samples varied between 0.03 and $0.96 \mathrm{mg} \mathrm{kg}^{-1}$, with an average value of $0.29 \mathrm{mg} \mathrm{kg}-1$ (Figure 1A). The soil and plant $\mathrm{Cd}$ concentrations generally exceeded the Chinese soil environmental quality risk control standard for soil contamination of agricultural land (GB 15618-2018; soil screening levels of 0.3 and $0.6 \mathrm{mg} \mathrm{kg}$, respectively, for $\mathrm{pH} \leq 7.5$ and $\mathrm{pH}>7.5)$ and food hygiene standards (GB 2762-2017, $<0.1 \mathrm{mg} \mathrm{kg}^{-1}$ ). The soil available Cd concentration varied between 0.0003 and $0.67 \mathrm{mg} \mathrm{kg}^{-1}$, with an average value of $0.07 \mathrm{mg} \mathrm{kg}^{-1}$ (Figure 1B). The extractable $\mathrm{Cd}$ was far less than the soil total $\mathrm{Cd}$; the average soil total $\mathrm{Cd}$ concentration was about 71 times that of the average extractable $\mathrm{Cd}$ concentration. Although the total $\mathrm{Cd}$ concentration in the soil was high, only a small proportion of this $\mathrm{Cd}$ could be absorbed by plants. The variation in soil total $\mathrm{Cd}$ and soil available $\mathrm{Cd}$ concentration are shown in Figures 1A,B. Previous studies found that the soil Cd significantly affected the Cd content of plants; for example, Liu et al., 2010 observed a significant difference $(p<0.05)$ in the Cd concentration of 40 Chinese cabbage shoots (from 0.88 to $7.76 \mathrm{mg} \mathrm{kg}^{-1}$ ) when the soil $\mathrm{Cd}$ concentration increased from 1.0 to $5.0 \mathrm{mg} \mathrm{kg}^{-1}$. However, Christopher et al., 2019 found that the Cd concentration in the flesh of potato was $0.2 \mathrm{mg} \mathrm{kg}^{-1}$ when the soil $\mathrm{Cd}$ concentration was lower than the detection limit. The results of experiments assessing the relationship between soil Cd content and plant $\mathrm{Cd}$ content have been inconsistent. Some studies have found that soil Cd levels were significantly related to plant $\mathrm{Cd}$ levels, while others have reported no relationship between these factors, perhaps due to the differences in plant species, climate, and other conditions.

The variation in BAFs calculated by Eq. 1 was relatively large (about three orders of magnitude), facilitating the study of Cd transfer from soil to plants (Figure 2A). This large variation may be due to the fact that the external environment, including soil properties, plant varieties, irrigation, and fertilizer management, differed among the various study fields (Liu, et al., 2015). Statistical methods have been used to describe the probability distribution characteristics of BAFs in order to analyze $\mathrm{Cd}$ accumulation in potatoes. In the present study, it was found that the major BAF of $\mathrm{Cd}$ for plant uptake was in the range of $0.005-1.40$, which is close to the BAF range found in a field survey of potatoes in four regions of New Zealand (Gray, et al., 2019). The critical value of the Cd concentration in soil may be deduced in terms of the limit of the $\mathrm{Cd}$ concentration in plants according to the measured bioaccumulation value $(\mathrm{BAF}=$ Cplant/Csoil, Cplant is $0.1 \mathrm{mg} \mathrm{kg}^{-1}$, which is the maximum value of $\mathrm{Cd}$ in potato tubers according to Chinese national food safety standards, and the corresponding Csoil is the soil $\mathrm{Cd}$ criteria) (Diao, et al., 2005). The soil Cd critical value of sampling soil sites can be used to fit the cumulative distribution curve of the soil threshold in order to prevent $\mathrm{Cd}$ contamination of potatoes in karst areas. In the present study, the soil Cd concentration that protected potatoes in $95 \%$ of soil sites was taken as the soil threshold of Cd. The resulting probability cumulative distribution can be built in many ways. For example, probability cumulative distribution functions, such as log-normal, log-logistic, or Burr type III, have been applied to study the cumulative distribution of the soil or water threshold of Cd. In general, it is necessary to estimate the potential risk of pollutants more conservatively for the risk assessment and derivation of soil environmental thresholds. In a previous study, the soil threshold of As for eight Chinese wheat varieties was calculated for 18 soils using cumulative probability distribution methods, including the Burr type III function, based on the protection of $95 \%$ of wheat varieties (Dai et al., 2016). In addition, hazardous concentrations of nonylphenol in the soil environment were estimated using probabilistic approaches based on acute and chronic species sensitivity distributions (Kwak, et al., 2017).

The cumulative probability distribution curve shown in Figure 2B characterizes the ecological risk to ecosystems; the potential affected fraction of $\mathrm{Cd}$ for the environment was calculated according to a given soil threshold $\mathrm{Cd}$ concentration (such as 0.3 or $0.6 \mathrm{mg} \mathrm{kg}^{-1}$ ). Furthermore, the distribution curve was also used to determine the soil threshold $\mathrm{Cd}$ concentration based on a given protection probability. For example, when the cumulative frequency was $20,80 \%(100-20 \%)$ of soil sites have a safe soil $\mathrm{Cd}$ concentration below the soil $\mathrm{Cd}$ threshold. In the present study, it was found that the soil $\mathrm{Cd}$ threshold for the study area was $0.15 \mathrm{mg} \mathrm{kg}^{-1}$ to protect the plant samples in $95 \%$ of the soil sites based on the cumulative probability distribution (cumulative frequency $=5 \%$ ) (Figure 2B). The cumulative probability distribution can also 
TABLE 2 | Pearson correlations between soil total $\mathrm{Cd}\left(\mathrm{Cd}_{\text {total }}\right)$, soil $\mathrm{CaCl}_{2}$ extractable $\mathrm{Cd}\left(\mathrm{Cd}_{\mathrm{CaCl}}\right)$, and plant $\mathrm{Cd}$ concentration ( $\left.\mathrm{Cd}_{\text {plant }}\right)$.

\begin{tabular}{|c|c|c|c|}
\hline & $\log \mathbf{C d}_{\text {total }}$ & $\log \mathrm{Cd}_{\mathrm{CaCl} 2}$ & $\log \mathbf{C d}_{\text {plant }}$ \\
\hline Log $\mathrm{Cd}_{\text {total }}$ & 1 & 0.083 & $0.499^{a}$ \\
\hline $\log \mathrm{Cd}_{\mathrm{CaCl} 2}$ & & 1 & $0.434^{a}$ \\
\hline Log Cdplant & & & 1 \\
\hline
\end{tabular}

be used to obtain other soil Cd thresholds for protecting different proportions of potatoes. The soil Cd threshold determined in this study as sufficient for protection of $95 \%$ of soil sites in karst areas was slightly lower than the Chinese soil environmental quality risk control standard for the contamination of agricultural soil (GB 15618-2018). These results indicate that potatoes grown in karst areas, in which tubers may more easily accumulate $\mathrm{Cd}$ from soil, may be more susceptible to soil $\mathrm{Cd}$ pollution in comparison with those grown in other areas.

\section{Prediction Model for Soil and Plant Cd Concentration}

Since the biochemical behavior of Cd in soil is complex, and many factors affect $\mathrm{Cd}$ uptake by plants, it is important to study the toxicity of $\mathrm{Cd}$ in mature crops in order to protect human health. Empirical regression can be used to estimate the rate of accumulation or transfer of heavy metals from soil to crops based on soil properties. For example, Liang et al., 2013 logtransformed the Cd content of spinach and soil to normalize variance and match a Freundlich-type function, and they added soil properties such as $\mathrm{pH}$ to the prediction model to improve its fitting accuracy. Liu et al., 2015 used a similar empirical method to fit a soil Cd threshold model using 18 Chinese soil types to prevent contamination of wheat by $\mathrm{Cd}$. In the present study, we found that $\log \mathrm{Cd}_{\mathrm{CaCl} 2}$ and $\log \mathrm{Cd}_{\text {total }}$ were both extremely significantly positively correlated with $\log \mathrm{Cd}_{\text {plant }}(p<0.01)$. The Pearson correlation coefficient was 0.434 for both $\log \mathrm{Cd}_{\mathrm{CaCl} 2}$ and $\log \mathrm{Cd}_{\text {plant }}$, where it was 0.499 for $\log \mathrm{Cd}_{\text {total }}$ and $\log \mathrm{Cd}_{\text {plant }}$ (Table 2). These results indicate that both the soil total $\mathrm{Cd}$ and the $\mathrm{CaCl}_{2}$-extracted $\mathrm{Cd}$ played an important role in $\mathrm{Cd}$ absorption by potato tubers. These findings are similar to those reported by Jun et al., 2018 from a study of the effects of alkaline amendment on Cd bioavailability in two Chinese cultivars of polished rice (Xiangwanxian 13 and Zhongyou 9,918) grown in paddy soil. A recent study using single extraction procedures, including methods utilizing EDTA, DTPA, $\mathrm{CH}_{3} \mathrm{COOH}$, and $\mathrm{HCl}$, revealed that the extractable $\mathrm{Cd}$ in soil was linearly correlated with the Cd concentration in wheat grains (Liu et al., 2019). These results are consistent with our findings, which showed a similar relationship between $\mathrm{Cd}$ in soil and plant samples.

A stepwise linear regression was performed to establish the relationship between $\log \mathrm{Cd}_{\text {soil }}$ (soil total $\mathrm{Cd}$ ), $\log \mathrm{Cd}_{\mathrm{CaCl} 2}$ (soil $\mathrm{CaCl}_{2}$-extracted $\left.\mathrm{Cd}\right)$, and soil $\mathrm{pH}$ and organic matter $(\mathrm{OM})(n=$ 105) based on Eq. 2. The results of the prediction models showed that $\mathrm{Cd}_{\text {total }}$ was significantly correlated with the soil $\mathrm{pH}$ and $\mathrm{OM}$, soil-extractable $\mathrm{Cd}_{\mathrm{CaCl} 2}$, and $\mathrm{Cd}_{\text {plant }}$; the $R^{2}$ value of the prediction model increased from 0.354 to 0.715 as the number of independent variables was increased (Table 3). Linear regression equations were obtained to describe the relationships between the total $\mathrm{Cd}$ concentration in soil and the $\mathrm{Cd}$ concentrations in wheat grains and roots $\left(R^{2}=0.62\right.$, 0.71 for grains and roots, respectively), as well as between the $\mathrm{CaCl}_{2}$-extracted $\mathrm{Cd}$ concentration in soil and the $\mathrm{Cd}$ concentrations in wheat grains and roots $\left(R^{2}=0.58,0.49\right.$ for grains and roots, respectively). A recent study indicated that the soil total $\mathrm{Cd}$ and $\mathrm{CaCl}_{2}$-extracted $\mathrm{Cd}$ were useful predictors of the Cd transfer from soil to plants (Qu, et al., 2020), which was in agreement with the results described in the present study. Soil $\mathrm{pH}$ was an important predictive factor, as shown by its presence in every prediction model in Table 3, and, among the independent variables in equation (4), $\mathrm{pH}$ contributed approximately $47 \%$ of the variance in the dependent variables.

Prediction of soil threshold Cd values by linear equations is more convenient than prediction by the cumulative probability analysis method. The soil threshold calculated by the empirical prediction equation was greater than that calculated by the probability statistic method. For example, the soil thresholds of Cd were $0.35,0.97$, and $1.60 \mathrm{mg} \mathrm{kg}^{-1}$ when the soil $\mathrm{pH}$ was $5.5,6.5$, and 7 , respectively, and the soil $_{\mathrm{CaCl} 2}, \mathrm{OM}$, and $\mathrm{Cd}_{\text {plant }}$ were $0.1 \mathrm{mg} \mathrm{kg}^{-1}, 10 \mathrm{~g} \mathrm{~kg}^{-1}$, and $0.1 \mathrm{mg} \mathrm{kg}^{-1}$, according to equation (4) in Table 3. Previous studies have shown that soil properties, especially $\mathrm{pH}$, are crucial factors influencing the transport of $\mathrm{Cd}$ between soil and vegetables. $\mathrm{pH}$ mainly affects the equilibrium distribution of heavy metal ions at the two-phase interface of soil and water, as well as the formation and dissolution of soil carbonate. Soil organic matter has a large number of functional groups, and its ability to adsorb $\mathrm{Cd}$ is much higher than that of other mineral colloids. Humic acid formed by decomposition can chelate (complex) with heavy metals, inhibiting the absorption of metals by plants. Using a stepwise regression model, Rafiq et al., 2014 concluded that Cd phytoavailability to pak choi was significantly affected by soil $\mathrm{pH}$, organic matter, and total $\mathrm{Zn}$ and $\mathrm{Cd}$ concentrations, and the $R^{2}$ of the stepwise regression model in their report was 0.977. Furthermore, through stepwise forward multiple regressions, McLaughlin et al. (1997) found that soil parameters such as $\mathrm{pH}$ and $\mathrm{Cl}$ were important influences on the $\mathrm{Cd}$ concentration of potato tubers. Furthermore, the measured soil Cd concentrations in the present study were close to the values predicted using equation (4) (Table 3) for a certain soil $\mathrm{Cd}$ concentration range (about $0-15 \mathrm{mg} \mathrm{kg}^{-1}$ ). The predicted soil $\mathrm{Cd}$ concentrations were greater than the measured values for higher soil Cd concentrations (Figure 3). In contrast with our results, a recent study reported no significant relationships between soil properties and the Cd concentration in potatoes in three field sites across New Zealand (Gray, et al., 2019). A recent study in Hunan province reported a soil Cd threshold of $1.819-3.272 \mathrm{mg} \mathrm{kg}^{-1}$ based on the safety limit of $\mathrm{Cd}$ in cereals $\left(0.2 \mathrm{mg} \mathrm{kg}^{-1}\right)$, which was higher than that permitted 
TABLE 3 | Prediction models for soil Cd concentration.

\begin{tabular}{|c|c|c|}
\hline Prediction equation & $\mathbf{R}^{2}$ & $p$ \\
\hline $\log \mathrm{Cd}_{\text {total }}=0.321 \mathrm{pH}-1.694$ & 0.354 & $<0.01$ \\
\hline $\log \mathrm{Cd}_{\text {total }}=0.521 \mathrm{pH}+0.481 \log$ soil $_{\mathrm{CaCl}_{2}}-2.159$ & 0.629 & $<0.01$ \\
\hline Log $\mathrm{Cd}_{\text {total }}=0.491 \mathrm{pH}+0.469 \log$ soil $_{\mathrm{CaCl} 2}+0.864 \log \mathrm{OM}-3.346$ & 0.679 & $<0.01$ \\
\hline $\log \mathrm{Cd}_{\text {total }}=0.436 \mathrm{pH}+0.348 \log$ soil $_{\mathrm{CaCl} 2}+0.804 \log \mathrm{OM}+0.519 \log \mathrm{Cd}_{\text {plant }}-2.785$ & 0.715 & $<0.01$ \\
\hline
\end{tabular}

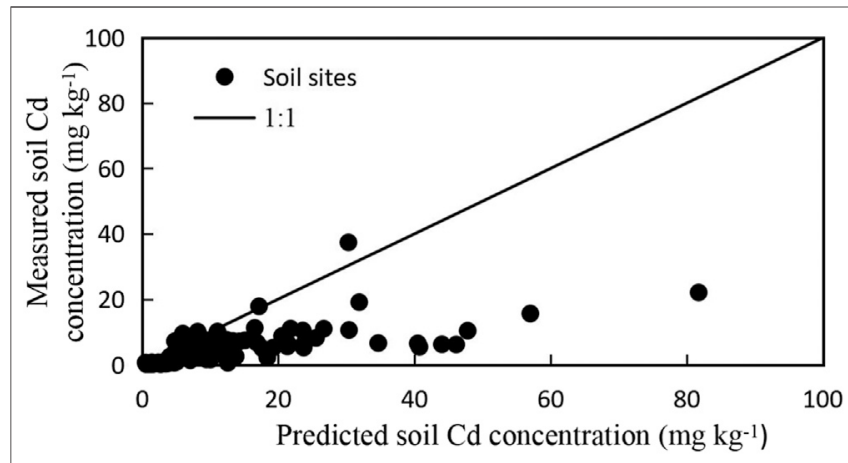

FIGURE 3 | Relationship between the measured and predicted soil Cd concentrations for different soil sites.

by the national soil environmental standards of China (Chen, et al., 2019). Using a prediction model, the threshold of soil total $\mathrm{Cd}$ in rootstalk vegetable fields in Guangdong was calculated to be $0.94 \mathrm{mg} \mathrm{kg}^{-1}$, which was also higher than the national soil Cd threshold in China (Sun, et al., 2013). Although the threshold values of Cd from studies performed in non-karst area were higher than those from our research, these differences are likely due to differences in soil conditions, pollution conditions, plant species, and other factors. Further research is required to compare $\mathrm{Cd}$ uptake rates and soil threshold values for karst and nonkarst areas.

\section{CONCLUSION}

In the frequency distribution of the BAF of potato tubers, BAF values from 0.1 to 0.3 occurred relatively frequently for soil $\mathrm{Cd}$ concentrations ranging from 0.15 to $37.4 \mathrm{mg} \mathrm{kg}^{-1}$. The transfer of

\section{REFERENCES}

Carla, O., Carlo, V., and Erik, S. (2007). Elevated Cadmium Concentrations in Potato Tubers Due to Irrigation with River Water Contaminated by Mining in Potosí, Bolivia. J. Environ. Qual. 36, 1181-1186. doi:10.1016/j.ecoenv.2016.04.031

Chen, Q., Peng, P., Hou, H., Ding, X., Long, J., au, X., et al. (2019). Effects of Soil Properties on the Cd Threshold in Typical Paddy Soils Using BCR Sequential Extraction. Hum. Ecol. Risk Assess. Int. J. 25, 2160-2173. doi:10.1080/10807039. 2018.1490998

Christopher, N., Shiv, P., Eman, E., Jaskaran, D., Ali, M., and Ramanbhai, P. (2019). Effect of Biochar on Heavy Metal Accumulation in Potatoes from Wastewater Irrigation. J. Environ. Manage. 232, 153-164. doi:10.1016/j.ecoenv.2016.04.031
Cd from soil with a high Cd concentration to potato tubers was found to be highly positively correlated with soil $\mathrm{pH}, \mathrm{OM}$, and $\mathrm{CaCl}_{2}$-extractable $\mathrm{Cd}\left(\mathrm{R}^{2}=0.715\right)$. The log-transformed plant $\mathrm{Cd}$ concentration was highly significantly correlated with the soil total $\mathrm{Cd}$ and soil $\mathrm{CaCl}_{2}$-extractable $\mathrm{Cd}$ concentrations, with Pearson correlations of 0.499 and 0.434 , respectively. The log-normal function was used to establish the cumulative probability distribution of the soil Cd threshold. Our results show that the probability model and empirical model can each adequately describe the transfer of $\mathrm{Cd}$ from soil to crops.

\section{DATA AVAILABILITY STATEMENT}

The original contributions presented in the study are included in the article/Supplementary Material, and further inquiries can be directed to the corresponding author.

\section{AUTHOR CONTRIBUTIONS}

$\mathrm{KL}$ analyzed the data and wrote the manuscript, HL revised the manuscript, XZ collected the samples, and ZC and XW provided important suggestions for the manuscript.

\section{FUNDING}

This research was supported by the Joint Projects of the National Natural Science Foundation of China (42067028) and the Science and Technology Planning Project of Guizhou Province, China (Qiankehejichu no. (2019)1103, Qiankehehoubuzu no. (2020) 3001).

Dai, Y., Lv, J., Liu, K., Zhao, X., and Cao, Y. (2016). Major Controlling Factors and Prediction Models for Arsenic Uptake from Soil to Wheat Plants. Ecotoxicology Environ. Saf. 130, 256-262. doi:10.1016/j.ecoenv. 2016.04 .031

Diao, W.-P., Ni, W.-Z., Ma, H.-Y., and Yang, X.-E. (2005). Cadmium Pollution in Paddy Soil as Affected by Different Rice (Oryza Sativa L.) Cultivars. Bull. Environ. Contam. Toxicol. 75, 731-738. doi:10.1007/s00128-005-0812-y

Ding, C., Ma, Y., Li, X., Zhang, T., and Wang, X. (2016). Derivation of Soil Thresholds for lead Applying Species Sensitivity Distribution: A Case Study for Root Vegetables. J. Hazard. Mater. 303, 21-27. doi:10.1016/j.jhazmat.2015. 10.027

Ding, C., Ma, Y., Li, X., Zhang, T., and Wang, X. (2018). Determination and Validation of Soil Thresholds for Cadmium Based on Food Quality Standard 
and Health Risk Assessment. Sci. Total Environ. 619-620, 700-706. doi:10.1016/ j.scitotenv.2017.11.137

François, M., Grant, C., Lambert, R., and Sauvé, S. (2009). Prediction of Cadmium and Zinc Concentration in Wheat Grain from Soils Affected by the Application of Phosphate Fertilizers Varying in Cd Concentration. Nutr. Cycl Agroecosyst 83, 125-133. doi:10.1007/s10705-008-9204-0

Gray, C. W., Yi, Z., Lehto, N. J., Robinson, B. H., Munir, K., and Cavanagh, J.-A. E. (2019). Effect of Cultivar Type and Soil Properties on Cadmium Concentrations in Potatoes. New Zealand J. Crop Hortic. Sci. 47, 182-197. doi:10.1080/ 01140671.2019 .1599028

Jun, M., Libin, Z., Lu, W., Xingmei, L., Caixian, T., Hongjin, C., et al. (2018). Contrasting Effects of Alkaline Amendments on the Bioavailability and Uptake of Cd in rice Plants in a Cd-Contaminated Acid Paddy Soil. Environ. Sci. Pollut. Res. Int. 25, 8827-8835. doi:10.1007/s11356-017-1148-y

Kara, E. E., Pirlak, U., and Özdılek, H. G. (2004). Evaluation of Heavy Metals' (Cd, $\mathrm{Cu}, \mathrm{Ni}, \mathrm{Ph}$, and $\mathrm{Zn}$ ) Distribution in Sowing Regions of Potato Fields in the Province of Niğde, Turkey. Water Air Soil Pollut. 153, 173-186. doi:10.1023/b: wate.0000019942.37633.31

Kwak, J. I., Moon, J., Kim, D., Cui, R., and An, Y.-J. (2017). Species Sensitivity Distributions for Nonylphenol to Estimate Soil Hazardous Concentration. Environ. Sci. Technol. 51, 13957-13966. doi:10.1021/acs.est.7b04433

Liang, Z., Ding, Q., Wei, D., Li, J., Chen, S., and Ma, Y. (2013). Major Controlling Factors and Predictions for Cadmium Transfer from the Soil into Spinach Plants. Ecotoxicology Environ. Saf. 93, 180-185. doi:10.1016/j.ecoenv.2013.04.003

Liu, K., Lv, J., He, W., Zhang, H., Cao, Y., and Dai, Y. (2015). Major Factors Influencing Cadmium Uptake from the Soil into Wheat Plants. Ecotoxicology Environ. Saf. 113, 207-213. doi:10.1016/j.ecoenv.2014.12.005

Liu, W., Zhou, Q., An, J., Sun, Y., and Liu, R. (2010). Variations in Cadmium Accumulation Among Chinese Cabbage Cultivars and Screening for Cd-Safe Cultivars. J. Hazard. Mater. 173, 737-743. doi:10.1016/j.jhazmat.2009.08.147

Liu, Z., Bai, Y., and Yang, T. (2019). Effect of Cd on the Uptake and Translocation of $\mathrm{Pb}, \mathrm{Cu}, \mathrm{Zn}$, and $\mathrm{Ni}$ in Potato and Wheat Grown in Sierozem. Soil Sediment. Contam. 28, 650-669. doi:10.1080/15320383.2019.1643289

McLaughlin, M. J., Maier, N. A., Rayment, G. E., Sparrow, L. A., Berg, G., au, A., et al. (1997). Cadmium in Australian Potato Tubers and Soils. J. Environ. Qual. 26, 1644-1649. doi:10.2134/jeq1997.00472425002600060026x

Mitchell, K., Mendoza-González, C. V., Ramos-Gómez, M. S., Yamamoto-Flores, L., Guerrero-Barrera, A. L., Macias-Medrano, R., et al. (2020). The Effect of Low-Temperature Biochar and its Non-pyrolyzed Composted Biosolids Source on the Geochemical Fractionation of $\mathrm{Pb}$ and $\mathrm{Cd}$ in Calcareous River Sediments. Environ. Earth Sci. 79. doi:10.1007/s12665-020-08908-5

Qu, X., Xu, W., Ren, J., Zhao, X., Li, Y., and Gu, X. (2020). A Field Study to Predict Cd Bioaccumulation in a Soil-Wheat System: Application of a Geochemical Model. J. Hazard. Mater. 400, 123135. doi:10.1016/j.jhazmat.2020.123135

Rafiq, M. T., Aziz, R., Yang, X., Xiao, W., Stoffella, P. J., Saghir, A., et al. (2014). Phytoavailability of Cadmium (Cd) to Pak Choi (Brassica Chinensis L.) Grown in Chinese Soils: A Model to Evaluate the Impact of Soil Cd Pollution on Potential Dietary Toxicity. PLoS One 9, e111461. doi:10.1371/journal.pone. 0111461
Römkens, P. F. A. M., Guo, H. Y., Chu, C. L., Liu, T. S., Chiang, C. F., and Koopmans, G. F. (2009). Prediction of Cadmium Uptake by Brown rice and Derivation of Soil-Plant Transfer Models to Improve Soil protection Guidelines. Environ. Pollut. 157, 2435-2444. doi:10.1016/j.envpol.2009.03.009

Sun, F. F., Wang, F. H., Wang, X., He, W., Wen, D., Wang, Q. F., et al. (2013). Soil Threshold Values of Total and Available Cadmium for Vegetable Growing Based on Field Data in Guangdong Province, South China. J. Sci. Food Agric. 93, 1967-1973. doi:10.1002/jsfa.6000

Tang, M., Lu, G., Fan, B., Xiang, W., and Bao, Z. (2021). Bioaccumulation and Risk Assessment of Heavy Metals in Soil-Crop Systems in Liujiang Karst Area, Southwestern China. Environ. Sci. Pollut. Res. 28, 9657-9669. doi:10.1007/ s11356-020-11448-x

Wei, Y., Jin, Z., Zhang, M., Li, Y., Huang, S., au, X., et al. (2020). Impact of Spent Mushroom Substrate on Cd Immobilization and Soil Property. Environ. Sci. Pollut. Res. 27, 3007-3022. doi:10.1007/s11356-019-07138-y

Xu, G., Zhang, S., Song, J., Brewer, R., and Gao, H. (2019). Cadmium Uptake in Radish (Raphanus Sativus L.) and Surficial Contamination: Implications for Food Safety and Local Soil Management. J. Soils Sediments 19, 3585-3596. doi:10.1007/s11368-019-02290-x

Yu, G., Chen, F., Zhang, H., and Wang, Z. (2021). Pollution and Health Risk Assessment of Heavy Metals in Soils of Guizhou, China. Ecosystem Health and Sustainability 7. doi:10.1080/20964129.2020.1859948

Zhang, J., Mu, G., Zhang, Z., Huang, X., and Fang, H. (2021). Speciation Variation and Bio-Activation of Soil Heavy Metals (Cd and Cr) in Rice-Rape Rotation Lands in Karst Regions. Int. J. Env. Res. Pub. He. 18. doi:10.3390/ ijerph18031364

Zhang, Z., Wu, X., Tu, C., Huang, X., Zhang, J., Fang, H., et al. (2020). Relationships between Soil Properties and the Accumulation of Heavy Metals in Different Brassica Campestris L. Growth Stages in a Karst Mountainous Area. Ecotox. Environ. Safe. 206. doi:10.1016/j.ecoenv.2020.111150

Zhou, W., Zhang, J., Zou, M., Liu, X., Di, X., Wang, Q., et al. (2019). Feasibility of Using rice Leaves Hyperspectral Data to Estimate CaCl2-Extractable Concentrations of Heavy Metals in Agricultural Soil. Sci. Rep.-UK 9. doi:10. 1038/s41598-019-52503-Z

Zogaj, M., and Düring, R.-A. (2016). Plant Uptake of Metals, Transfer Factors and Prediction Model for Two Contaminated Regions of Kosovo. J. Plant Nutr. Soil Sci. 179, 630-640. doi:10.1002/jpln.201600022

Conflict of Interest: The authors declare that the research was conducted in the absence of any commercial or financial relationships that could be construed as a potential conflict of interest.

Copyright $\odot 2021 \mathrm{Liu}, \mathrm{Liu}$, Zhou, Chen and Wang. This is an open-access article distributed under the terms of the Creative Commons Attribution License (CC BY). The use, distribution or reproduction in other forums is permitted, provided the original author(s) and the copyright owner(s) are credited and that the original publication in this journal is cited, in accordance with accepted academic practice. No use, distribution or reproduction is permitted which does not comply with these terms. 